\title{
Mathematical Driving Model Based Evaluation of Losses Components in the Control Systems with Induction Motor Drive
}

\author{
AHMED IBRAHIM JABER ALZUBAYDY \\ Electrical power and machines Engineering Department \\ College of engineering-Diyala University \\ Msc.Ahmed.I.J@engineering.uodiyala.edu.iq \\ heroiraq@mail.ru \\ Iraq - diyala-baquba
}

\begin{abstract}
This paper is investigate the modelling of three phase ,two level inverter connected to three phase induction motor. This system divided to two parts, system control (inverter frequency) and three phase induction motor. The modelling of this systems are built up by Method of Interconnected Subsystem decomposition of a that are coupled by means of dependent voltage and current sources. Such an approach ensured high adaptability in reliability of the work models in conjunction with worthy precision of calculation. The model reflected the mean coupling with basic properties of real machines and enables to calculate transient and steady-state responses as well as to evaluate components of energy losses in the system, adopting the programs $(\mathrm{C}++$ and $\mathrm{C}$ builder) explore the optimization case from the systems, when the varying leakage inductance in rotor windings, then the losses in both rotor and stator in induction motor have deferent variation so its impacted of the current displacement in rotor winding. Several of calculations are done for different numbers of pole to estimate suitable coefficient of load parameters.
\end{abstract}

Keywords:- Mathematical model, three phase IM- two level inverter, Interconnected Subsystem , C ++ and C builder language.

\section{INTRODUCTION}

Mathematical driving model of the system with IM are commonly used to simplify and improve investigation and mending of electromechanical structure . Obviously, main time for the system developed, archived great tension, depends on model completeness and agreement with real machine characteristics.

Modelling of AC machines analysing in $\mathrm{C}++$ and $\mathrm{C}$ builder ,taking in account design and operation features of the machines such as multiphase windings, iron saturation, energy losses, including stray load losses, high frequency losses in IM, and losses in SC. In same cases defects of the models mentioned above result in inconsistency of results as to, for instance, starting characteristics, assessment of machine efficiency. At the same time as it is seen from publications [1] - [3] evaluation of energy losses is of great importance.

The model figure 1 described is built up due decomposition of complex systems into sub circuits interconnected via dependent voltage and current sources [4]-[6].

This document is a template. An electronic copy can be downloaded from the conference website. For questions on paper guidelines, please contact the conference publications committee as indicated on the conference website. Information about final paper submission is available from the conference website.

Before submitting your final paper, check that the format conforms to this template. Specifically, check the appearance of the title and author block, the appearance of section headings, document margins, column width, column spacing and other features. 


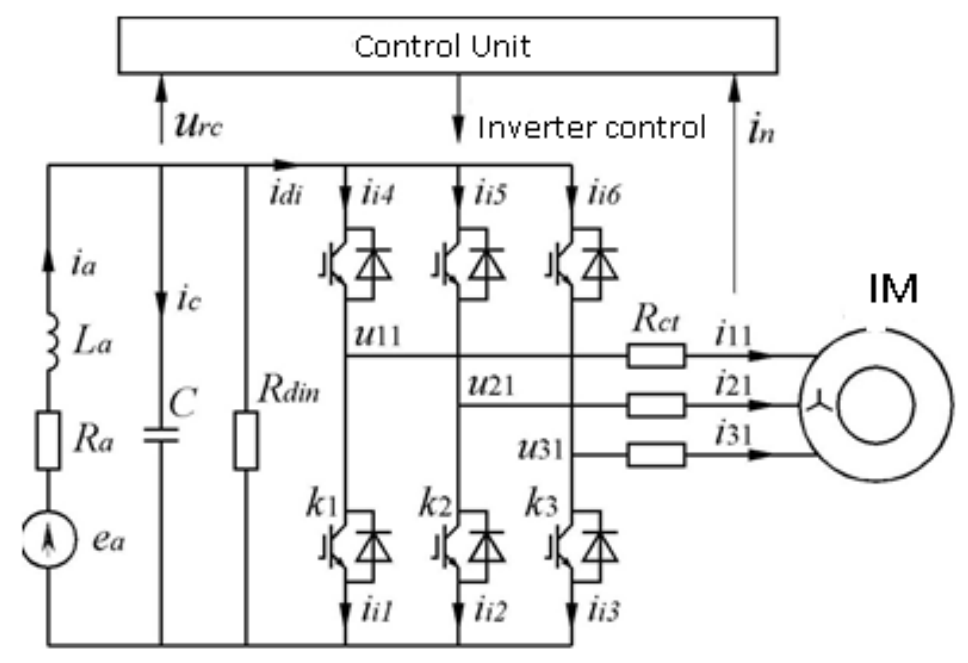

Figure 1 sub scheme of the system with two-level inverter with induction motor drive.

\section{MATHEMATICAL ANALYSIS FOR THREE PHASE TWO LEVEL INVERTER WITH INDUCTION MOTOR IM}

The model of inverter connected to three-phase induction motor has handle real parameters (rated power $500 \mathrm{KW}$ and suppled voltage 380) etc. Computer models of The mathematical analysis system is dividing into sub circuit, interconnected dependent voltage, and current sources. As a result represented sub circuit shown in Fig 2

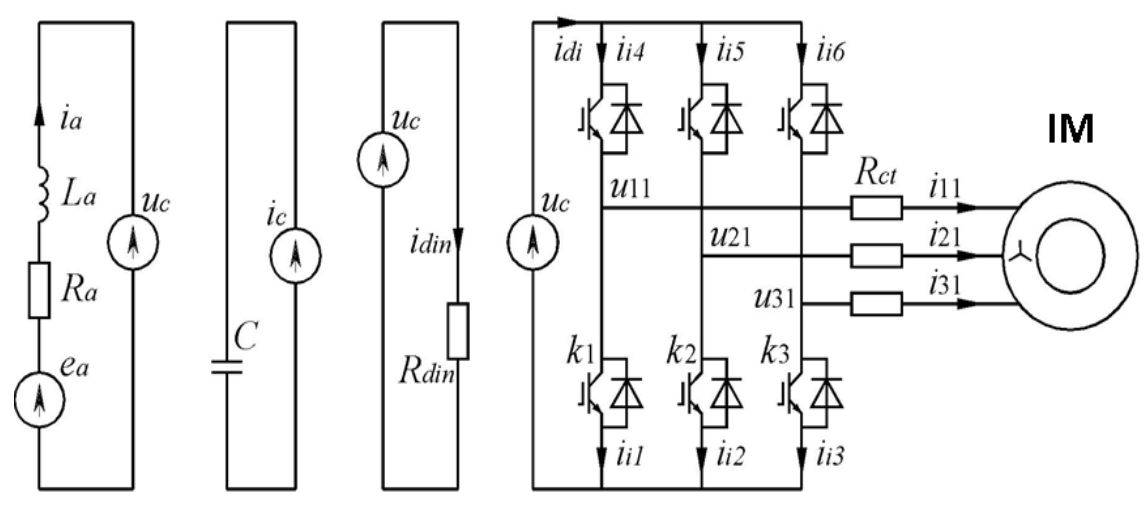

Figure 2 Dividing sub scheme of the system with two-level inverter with induction motor drive.

A further transformation circuits shown in figure 3.
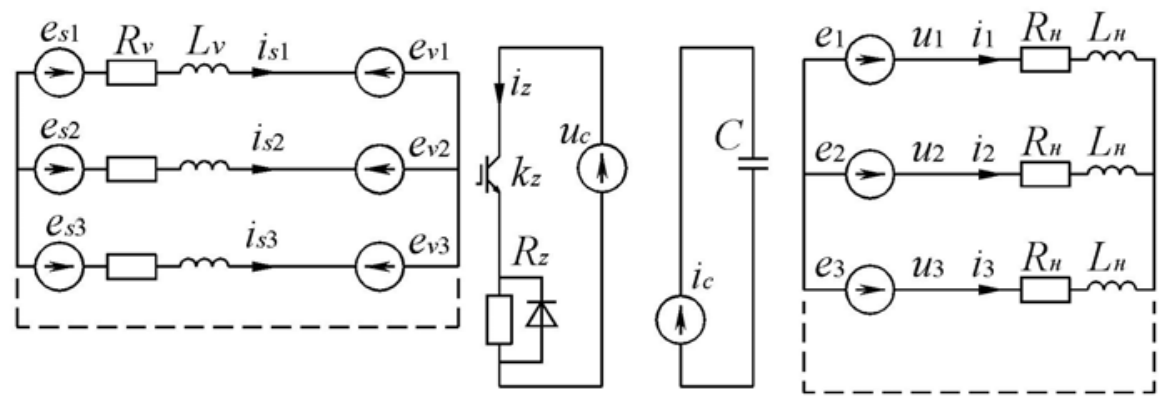

Figure 3 transformation schemes

The removal from the EMF phases $\mathrm{AB}$ and zero sequence components of the VSI shown in equations $(1,2)$ below. 
$e_{v 0}=\frac{e_{v 1}+e_{v 2}+e_{v 3}}{3}$

$u_{v n}=e_{v n}-e_{v 0}, \quad n=1,2,3$

$e_{0}=\frac{e_{1}+e_{2}+e_{3}}{3}$

$u_{n}=e_{n}-e_{0}, \quad n=1,2,3$

A continue transformation circuits shown in figure 4 .
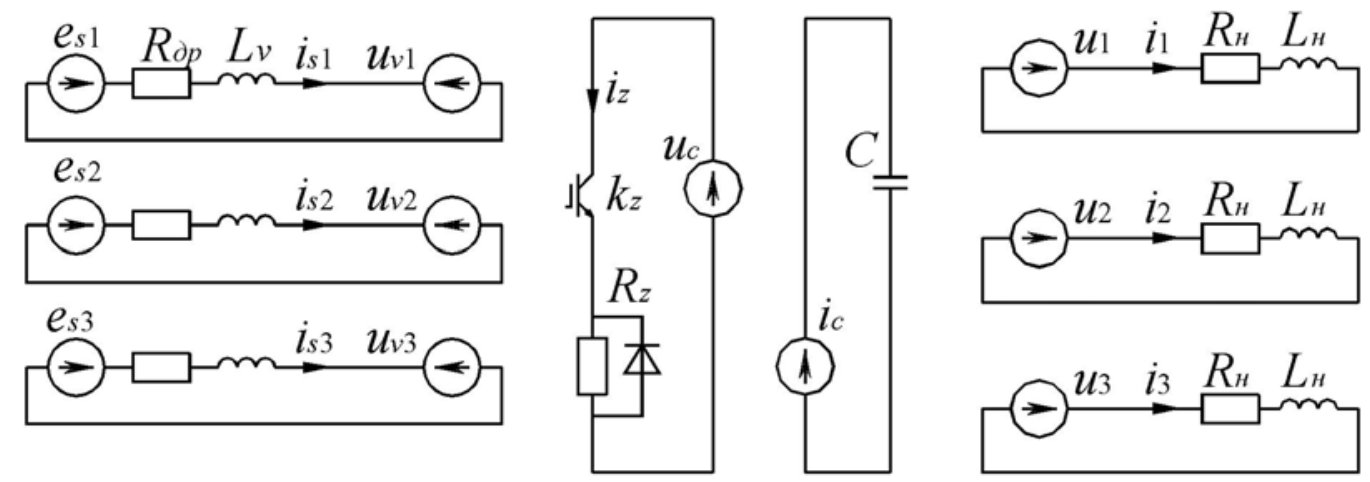

Figure 4 Removal from the EMF phases IM and zero sequence components of the VSI

Other identification parameter gradjualy such the EMF phase of network shown in equation 3 below

$e_{s n}=E_{s m} \sin \left[\tau-\frac{2 \pi}{3}(n-1)\right]$.

When $\tau=\tau+\omega \cdot \Delta t$.

The derivatives current power supply shown in equation 4 below.

$\frac{d i_{s n}}{d t}=\frac{1}{L_{s}}\left(e_{s n}-u_{v n}\right), \quad n=1,2,3$.

So the derivatives phase currents rectifier shown in equation 5 below.

$\frac{d i_{v n}}{d t}=\frac{1}{L_{v}}\left(u_{s n}-u_{v n}-R_{v} \cdot i_{v n}\right), \quad n=1,2,3$.

The currents in the arms $\mathrm{AB}$ of the bridge shown in equation 6.

$i_{n}=k_{v n} i_{v n}$,

$i_{n+3}=\left(1-k_{v n}\right) i_{v n}$.

$\mathrm{AB}$ bridge rectified current shown in equation (7) below.

$i_{v d}=i_{v 1}+i_{v 2}+i_{v 3}$.

The current protection circuit shown in equation 8 .

$i_{z}=k_{z} u_{c} / R_{z}$

The currents in the bridge arms VSI shown in equation 9.

$i_{i n}=k_{i n} i_{n}, \quad i_{i n+3}=\left(1-k_{i n}\right) i_{n}$

The input current of the transistor bridge VSI shown in equation 10 .

$i_{i d}=i_{i 1}+i_{i 2}+i_{i 3}$.

The current of capacitor shown in equation 11 . 
$i_{c}=i_{v d}-i_{z}-i_{d i}$.

Such the derivatives the load phase currents shown in equation 12.

$$
\frac{d i_{n}}{d t}=\frac{1}{L_{H}}\left(u_{n}-R_{H} \cdot i_{n}\right)
$$

These equations mentioned above present the mathematical inverter model behaver through operating system.

\section{INDUCTION MOTOR WITH AN ARBITRARY NUMBER THREE-PHASE WINDINGS AND SQUIRREL CAGE. [10]}

The mathematical expiration of the induction machines(IM) are mainly consisted with semiconductors, converters (inverter frequency) in such systems phase voltages and currents of the stator winding machines may have significant alteration As the number of decrease-pate in energy losses in the rotor phase of the harmonic structure of higher spatial-decisive. The multiphase structure is particularly impact high speed machines, in which the weight and volume of active elements is relatively small. Then there is a problematic issue to reduce the surface energy losses in the rotor. That's cause increasing in the stator phase numbers windings to reduce the energy loss in the rotor of the higher harmonic components. The growth of numbers of phases reduced also the energy losses in the rotor side of the high rotation (3Ph) harmonics components. The other options are multiphase constructions could particularly active in high-speed machines, The machine windings are mutually phase-shifted by the ratio of $60 \mathrm{e}$. deg. to the number of windings. The zero point of the windings is withdrawn so the rotor is short-circuited and the asynchronous machine is configured similarly to the description of synchronous machines in separating it into a sub circuit interconnected through a dependent sources of voltage and current, as shown in fig.3. Directions of currents and voltages had taken in IM machine (for generator mode). The stator windings are presented in the following phase axes notation $\mathrm{n}$ - phase number $(\mathrm{n}=1,2,3) ; \mathrm{m}$ - number of winding $(\mathrm{m}=1, . . \mathrm{M}), \mathrm{M}$ - the number of three-phase windings, $\mathrm{U}_{\mathrm{nm}}-$ phase voltage, $\mathrm{I}_{\mathrm{nm}}$ - phase currents. The sub circuit's stator windings as dependent sources considered EMF phase $\left.\mathrm{e}_{\mathrm{nm}}\right)$ Due to the magnetic flux in the gap), and the mutual induction electromotive force along paths $\mathrm{E}_{\mathrm{snm}}$ scattering phases, Taken into account the phase inductance $\mathrm{L}$ and active resistance $\mathrm{r}_{1}$. $\mathrm{E}_{\mathrm{snm}}$ EMF and inductance $\mathrm{L}$ are determined using the following parameters: $\mathrm{L}$ - the inductance of the phase dispersion in a symmetric mode, all the windings, $1_{\mathrm{s} 1}$ - inductance of phase scattering in a symmetric mode, a three-phase winding (other open), and $1_{0}$ - zero sequence inductance. The three-phase machines $\mathrm{L}=1$. If the zero point of the three-phase windings is isolated, then 10 inductance can be taken as such, ls1. Rotary contours described in mutually perpendicular axes $\mathrm{d}$ and $\mathrm{q}$, not under example, $1_{\mathrm{s} 1}$. Rotary outlines described in mutually perpendicular axes $\mathrm{d}$ and $\mathrm{q}$, not under the rotor Vision. The rotor sub circuits loops on axes $\mathrm{d}$ and $\mathrm{q}$ as dependent sources incorporated currents $I_{d}$ and $I_{q}$ reaction anchor. It takes into account the magnetizing inductance $1_{m}$, resistance circuit magnetization $\mathrm{rm}$, rotor winding leakage inductance $1_{\mathrm{s} 2}$ and active rotor winding resistance $\mathrm{r}_{2}$. On fig. 3 direction indicated current and voltage sources, and the directions of the axes $\mathrm{d}$ and $\mathrm{q}$ axes $\alpha$ and $\beta$, the rotational direction of the rotor with the frequency $\omega, \tau$ the angle of rotation of the rotor $\mathrm{d}$ axis relative to the axis $\alpha$.

In which the weight and volume of actual elements is relatively small, and there is a problem of reducing the dissipating energy 1 in the rotor. The mathematical description of 3-phase machine with multi-phase IM machine. The following inductance is shown in equation 13.

$$
L=2 l_{s 1}-l_{s m}, l_{a}=M\left(l_{s m}-l_{s 1}\right), l_{b}=\left(l_{0}-l\right) / 3
$$

Also the coefficients are shown in equations $(14,15,16$ and 17).

$$
\begin{aligned}
& C_{n m}=\cos \left[\frac{2 \pi}{3}\left(n-1+\frac{m-1}{2 m}\right)\right] \\
& S_{n m}=\sin \left[\frac{2 \pi}{3}\left(n-1+\frac{m-1}{2 m}\right)\right] \\
& C_{m}=\cos \left[\frac{\pi}{M}(m-1)\right] \\
& S_{m}=\sin \left[\frac{\pi}{M}(m-1)\right]
\end{aligned}
$$

For sub circuits, derivatives of the stator currents windings are presented in 18 .

$$
\frac{d i_{n m}}{d t}=\frac{1}{l+l_{s t}}\left(e_{n m}+e_{s n m}-u_{n m}-r_{1} i_{n m}+l_{s t} \frac{d i_{n m}}{d t}\right)
$$

When $1_{\text {st }}$ - stabilizing inductance. 
Mutual effect the phases in the ways of the scattering and the currents of the armature reaction are determined by using the following variables from Derivatives of currents in $\alpha \beta_{0}$ - frame shown in equation 19,20,21, and 22 .

$$
\begin{aligned}
& \frac{d i_{\alpha}}{d t}=\frac{2}{3 M} \sum_{m=1}^{M} \sum_{n=1}^{3} c_{n m} \frac{d i_{n m}}{d t} \\
& \frac{d i_{\beta}}{d t}=\frac{2}{3 M} \sum_{m=1}^{M} \sum_{n=1}^{3} s_{n m} \frac{d i_{n m}}{d t} \\
& \frac{d i_{\alpha 0}}{d t}=\sum_{m=1}^{M} c_{m} \sum_{n=1}^{3} \frac{d i_{n m}}{d t} \\
& \frac{d i_{\beta 0}}{d t}=\sum_{m=1}^{M} s_{m} \sum_{n=1}^{3} \frac{d i_{n m}}{d t}
\end{aligned}
$$

EMF mutual inductance of stator windings in the leakages path are shown in equation 23.

$$
e_{s n m}=-l_{\alpha}\left(c_{n m} \frac{d i_{\alpha}}{d t}+s_{n m} \frac{d i_{\beta}}{d t}\right)-l_{b}\left(c_{m} \frac{d i_{\alpha 0}}{d t}+s_{m} \frac{d i_{\beta 0}}{d t}\right)
$$

Where- $l_{a}=M\left(l_{s m}-l_{s 1}\right) l_{b}=\left(l_{0}-l\right) / 3 \quad$ zero-sequence inductance.

The currents of armature reaction of the two orthogonal axes $\alpha$ and $\beta$ shown in equations 24,25 .

$i_{\alpha}=\frac{2}{3 M} \sum_{m=1}^{M} \sum_{n=1}^{3} c_{n m} i_{n m}$

$$
i_{\beta}=\frac{2}{3 M} \sum_{m=1}^{M} \sum_{n=1}^{3} s_{n m} i_{n m}
$$

Armature reaction current along the rotational coordinate $d$ and q shown in equations 26,27

$i_{d}=i_{\alpha} \cos \tau+i_{\beta} \sin \tau$

$i_{q}=i_{\alpha} \sin \tau-i_{\beta} \cos \tau$

Derivatives reaction armature currents beside the axes $\mathrm{d}$ and $\mathrm{q}$ shown in equation 28,29

$$
\begin{aligned}
& \frac{d i_{d}}{d t}=\frac{d i_{\alpha}}{d t} \cos \tau+\frac{d i_{\beta}}{d t} \sin \tau-\omega \cdot i_{q} \\
& \frac{d i_{q}}{d t}=\frac{d i_{\alpha}}{d t} \sin \tau-\frac{d i_{\beta}}{d t} \cos \tau+\omega . i_{d}
\end{aligned}
$$

The currents of rotor loops in axes $\mathrm{d}$ and $\mathrm{q}$ are determined from the following equations 30,31

$$
\frac{d i_{a d}}{d t}=\frac{l_{s 2} \frac{d i_{d}}{d t}-r_{m} i_{a d}+r_{2} i_{2 d}}{l_{m}+l_{s 2}},
$$

Where $i_{2 d}=i_{d}-i_{a d}$

$$
\frac{d i_{a q}}{d t}=\frac{l_{s 2} \frac{d i_{q}}{d t}-r_{m} i_{a q}+r_{2} i_{2 q}}{l_{m}+l_{s 2}}
$$

Where $i_{2 q}=i_{q}-i_{a q}$

Projections of EMF in the axis d- q induction motor shown in equations 32,33.:

$e_{d}=-l_{m}\left(i_{a q} \omega+\frac{d i_{a d}}{d t}\right)$ 
$e_{q}=l_{m}\left(i_{a d} \omega-\frac{d i_{a q}}{d t}\right)$

The transformation of EMF from d-q axis to the axes $\alpha$ and $\beta$ shown in equations below 34, 35 .

$e_{\alpha}=e_{d} \cos \tau+e_{q} \sin \tau$

$e_{\beta}=e_{d} \sin \tau-e_{q} \cos \tau$

The EMF Phase produced by magnetizing flux shown in equation 36 .

$e_{n m}=e_{\alpha} c_{n m}+e_{\beta} s_{n m}$

The electromagnetic rotating torque of machine shown in equation 37

$M_{\ni M}=\frac{3 M}{2} l_{m}\left(i_{a d} i_{q}-i_{a q} i_{d}\right)$

Rotational speed bipolar machines at the moment of inertia $\mathrm{J}$ is determined by an electromagnetic torque $\mathrm{M}_{\mathrm{EM}}$ and the opposing torque on the shaft $\mathrm{M}_{\mathrm{c}}$ (torque of the prime mover for a generator or resistance point for the motor ) shown in equation 38 .

$$
\frac{d \omega}{d t}=\frac{1}{J}\left(M_{c}-M_{\ni M}\right)
$$

If the losses of steel, mechanical and additional energy losses are taken into account before the additional torque-resistance of the machine shaft, instead the equations shown below 39, 40, and 41

$$
M_{\mathrm{p}}=M_{m e c h}\left(\frac{\omega}{\omega_{n}}\right)^{2}+M_{c m n}\left(\frac{\omega}{\omega_{n}}\right)^{1.3}\left(\frac{I_{a m}}{I_{a m n}}\right)^{2}
$$

Where $\mathrm{M}_{\text {mech }}$-rotational torque conditioned mechanical energy losses in nominal mode, $\mathrm{M}_{\mathrm{cmn}}$-rotational torque due to energy losses in the steel in nominal mode, ${ }^{\omega_{n}}$-rated speed rad/s, $\mathrm{I}_{\mathrm{am}}$ - magnetizing current and $\mathrm{I}_{\mathrm{amn}}{ }^{-}$ nominal value of magnetizing current. In accordance with (38), the shaft torque due to mechanical losses is proportional to the square of the speed. And the torque due to losses in the steel, the magnetizing current is proportional to the second power and frequencyl.3 degree rotation. Equation (38) can be converted to equation 39.

$$
M_{\mathrm{p}}=\left(\frac{\Delta \mathrm{P}_{\mathrm{mech}} * \omega^{2}}{\omega^{3}{ }_{n}}\right)+\left(\frac{\Delta \mathrm{P}_{\mathrm{cmn}} * \omega^{1.3}}{\omega^{2.3}{ }_{n}}\right)^{1.3}\left(\frac{I_{a m}}{I_{a m n}}\right)^{2}
$$

Where $\Delta \mathrm{P}_{\text {mech- }}$ mechanical power in rated operation, $\Delta \mathrm{P}_{\mathrm{cmn}}-$ Losses power in steel in rated mode ,and magnetizing current equal $i_{a d}={\sqrt{\mathrm{aq}^{2}}{ }^{2}+i_{a d}{ }^{2}}^{2}$, and In this case rotational frequency of the bipolar machine at the moment of inertia $J$ are determined by an electromagnetic torque Mem, counteracting torque on the shaft $\mathrm{Mc}$ (torque of the prime mover for a generator or resistance point for the motor ) and torque $\mathrm{M}_{\mathrm{p}}$ losses shown in equation 41.

$$
\frac{d \omega}{d t}=\frac{1}{J}\left(M_{c}-M_{e, M}-M_{p}\right)
$$

The multi-pole machines $M_{e_{M}}$ and $\omega$ are determined based on the number of pole pairs.

\section{MODULATION SYSTEM CONTROL AND CALCULATION TRANSIENT AND STEADY STATE REGION.}

The modeling system is interconnected sub circuit with induction motor to calculate transient and steady state by using software packages $\mathrm{C}++$ Builder and visual $\mathrm{C}++$ Language. Taking Effect of current displacement in the rotor winding of the rated power of motor is $500 \mathrm{~kW}$ and rated voltage $380 \mathrm{~V}$. Several calculations for the different numbers of pole in the rotor (3-5) are improved for resistance 1.3, and 1.2 Inductance. Get the value of starting torque and the nominal stator current same procedure through the equation (42), and 43.Models of VSI for reference load power motor of $500 \mathrm{KW}$ and voltage 380 . 


$$
\begin{aligned}
& I_{1 n}=\frac{P n}{\sqrt{3 * U_{1 n} * \cos \vartheta}} \\
& I_{1 n}=\frac{500000}{\sqrt{3} * 380 * 0.839}=905.44 \mathrm{~A} \\
& M p=\frac{m 1 * U 1^{2} * R_{2}}{\omega_{1 n} *\left[\left(R_{1}+R_{2} \cdot\right)^{2}+\left(X_{1}+X_{2}\right)^{2}\right]}= \\
& \frac{3 * 380^{2} * 0.0165 / 0.0125}{157 *\left[(2.173+0.0165)^{2}+(0.06664+0.0005 / 0.0125)^{2}\right]}=12.45 \mathrm{NM}
\end{aligned}
$$

To highlight mathematical divine of the system inverter frequency feeding induction motor to characteristics, calculation of rated operation regine of inverter frequency (control system) and induction motor was implemented for The frequency of the reference voltages of $1 \mathrm{kHz}$. The table (1) represents input data(parameter system ) and table 2 input data of control system

TABLE I Input data

\begin{tabular}{|l|l|l|c|}
\hline \multirow{2}{*}{ No } & \multicolumn{3}{|c|}{ All parameters of motor and driver } \\
\cline { 2 - 4 } & \multicolumn{1}{|c|}{ Name } & Symbol & Value \\
\hline 1 & The number of bridges & NumM & 1 \\
\hline 2 & Three-phase windings of motor & M_obm & 1 \\
\hline 3 & The number of branches in the rotor & M_rot & 4 \\
\hline 4 & EMF sources & Ei & 380. \\
\hline 5 & The inductance of the source H & Li & 0.00001 \\
\hline 6 & Active source of resistance, Ohm & Ri & 0.0001 \\
\hline 7 & The capacity of the capacitor bank, & $\mathrm{C}$ & 0.008 \\
\hline 8 & The resistance of the capacitor bank, Ohm & Rc 0.0001 & 0.0001 \\
\hline 9 & The resistance of the protective resistor, Ohm & Rz & 5000. \\
\hline 10 & Leakage inductance phase reactor, H & Ldr & 0.0000000001 \\
\hline 11 & mutual Inductance mutual of induction phase reactor, H & Ldrm & 0.00000000001 \\
\hline 12 & The resistance of the phase throttle Ohm & Rdr & 0.000000 \\
\hline 13 & The specified module temperature, c & Tmod & 100. \\
\hline 14 & Multiplicity of dynamic losses & Kd & 1.35 \\
\hline 15 & The time constant of the loss of the filter, with Tdin & Tdin & 0.2 \\
\hline 16 & Lost count? & CalcD & 1. \\
\hline 17 & The magnetic coupling in phase choke coil on the other? & DrPhIn & 0. \\
\hline 18 & The nominal angular frequency of Voltage. & . SM, rad / s . & 182,841 \\
\hline 19 & Rated power factor & cn & 0.839 \\
\hline 20 & Nominal active power SM, kW . & pdn . & 500. \\
\hline 21 & Rated operating voltage linear cm, & vdn & 661. \\
\hline 22 & Rated slip of IM & snom & 0.0125 \\
\hline 23 & Efficiency of IM & KPD & 0.94149 \\
\hline 24 & Moment of inertia (reduced to the stator frequency), $\mathrm{kg} *$ & Jd & 50. \\
\hline 25 & $\begin{array}{l}\text { inductance. phase scattering at work of all the windings, } \\
\text { pu }\end{array}$ & LsM & 0.06664 \\
\hline 26 & Inductance. scattering phases in the one coil pu. & Ls1 & 0.06664 \\
\hline 27 & Inductance. rotor leakage, pu. & Lr2 & 0.0005 \\
\hline 28 & Inductance residual, pu & Lo & 0.06664 \\
\hline 29 & Magnetizing inductance (sat.), Pu & Lm & 2.0 \\
\hline & & & \\
\hline & & \\
\hline
\end{tabular}




\begin{tabular}{|l|l|l|c|}
\hline 30 & The resistance of the stator phases, $\mathrm{pu}$ & $\mathrm{R} 1$ & 0.0165 \\
\hline 31 & The resistance of the rotor phase, $\mathrm{pu}$ & $\mathrm{R} 2$ & 2.173 \\
\hline 32 & The resistance circuit magnetization $\mathrm{pu}$ & $\mathrm{Rm} 1$ & 78.3 \\
\hline 33 & Resistance ext. circuit pu & $\mathrm{Rm} 2$ & 78.3 \\
\hline 34 & Mechanical losses in steel and additional $\mathrm{kW}$ & $\mathrm{Wmex}$ & 0.4 \\
\hline 35 & The initial position of the rotor, c. & Tau & 0. \\
\hline 36 & The initial speed, pu & Omega. & 0. \\
\hline 37 & Inductance. rotor leakage, pu. & $\mathrm{Lr} 2$ & 0.0105 \\
\hline 38 & The resistance of the rotor phase, pu & $\mathrm{R} 2$ & 0.4346 \\
\hline 39 & Inductance. rotor leakage, pu. & $\mathrm{Lr} 2$ & 0.0025 \\
\hline 40 & The resistance of the rotor phase, pu & $\mathrm{R} 2$ & 0.08692 \\
\hline 41 & Inductance. rotor leakage, pu. & $\mathrm{Lr} 2$ & 0.0125 \\
\hline 42 & The resistance of the rotor phase, pu & $\mathrm{R} 2$ & 0.01738 \\
\hline 43 & The specified speed, pu. & $\mathrm{Oz}$ & 1. \\
\hline
\end{tabular}

Also the Table (2) represented input data for control system.

Table (2) Input data for control system

\begin{tabular}{|c|c|c|c|}
\hline \multirow[t]{2}{*}{ No } & \multicolumn{3}{|l|}{ All parameters of motor and driver } \\
\hline & Name & Symbol & Value \\
\hline 1 & The frequency of the reference voltages, $\mathrm{Hz}$ & Fop & 1000. \\
\hline 2 & Rated load frequency voltage, $\mathrm{rad} / \mathrm{s}$ & f1 & 29.1 \\
\hline 3 & The lower limit frequency IM, Hz & flmn. & 1. \\
\hline 4 & The upper limit frequency of IM, Hz & flmx & 30. \\
\hline 5 & The main component. Voltage control in nominal mode, pu & Uy1n & 1.0273 \\
\hline 6 & Limit 1 harmonic control voltage, $\mathrm{pu}$ & Uymx & 1.0273 \\
\hline 7 & initial excitation time, $\mathrm{s}$ & Tnw & 0.5 \\
\hline 8 & Voltage frequency. control. with initial excitation, $\mathrm{Hz}$ & Fnw & 1.1 \\
\hline 9 & Time $100 \%$ change in frequency of the input signal, & Toz & 3.0 \\
\hline 10 & The time constant of a given frequency filter, $\mathrm{s}$ & To1 & 0.2 \\
\hline 11 & the rectified voltage filter time constant, $\mathrm{s}$ & $\mathrm{Tu}$ & 0.1 \\
\hline 12 & The extent of the frequency corrections ( 0 to 1 ) at Voltage. & KUd & 0.5 \\
\hline 13 & The maximum allowable rectified voltage, $\mathrm{V}$ & Ucmx & 1500. \\
\hline
\end{tabular}

Consuming the parameters in Table (3) below of leakages inductance in rotor for induction motor relies improvement in the losses values

Table (3) rotor leakage inductances

\begin{tabular}{|c|c|c|c|c|}
\hline No.of case & $\begin{array}{c}\text { Leakage flux in } \\
\text { Phase A }\end{array}$ & $\begin{array}{c}\text { Leakage flux in } \\
\text { Phase B }\end{array}$ & $\begin{array}{c}\text { Leakage flux } \\
\text { in Phase C }\end{array}$ & Units \\
\hline Case1 Ls2 & 0.0125 & 0.0105, & 0.0025 & $\mathrm{Pu}$ \\
\hline Case2 Ls2 & 0.015 & 0.003 & 0.0126 & $\mathrm{Pu}$ \\
\hline Case3 Ls2 & 0.2 & 0.24 & 0.288 & $\mathrm{Pu}$ \\
\hline
\end{tabular}




\section{ALGORITHM CALCULATIONS PROGRAMS}

Figure 4 shows the flowchart programming for calculation and solution equation by using $\mathrm{C}++$ and visual $\mathrm{C}++$ [8].

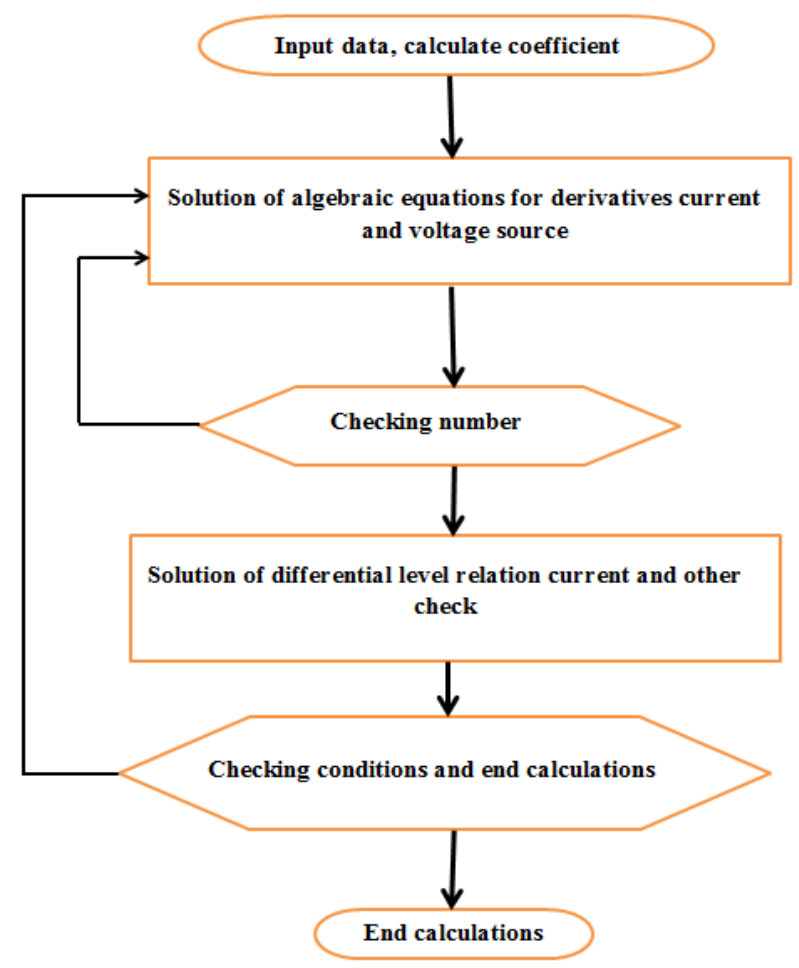

Figure 4 Algorithm calculations programs

The results in tables 4,5 and 6 show the losses variation with different leakage inductance value of the rotor, when the variation range is shown in table 3. Figure 5,6,7,8,9 and 10 represent the values of capacitor voltage, phase voltage , three phase currents, electromagnetic torque and voltage control (modulation signal for carrier frequency $1 \mathrm{KHz}$ ).

Table (4) Harmonic analysis when Lr2 0.0125, 0.0105, 0.0025 pu

\begin{tabular}{|c|c|}
\hline Name & Value/Units \\
\hline Input capacitor voltage & $377.693 \mathrm{~V}$ \\
\hline Stator copper losses & $17.724 \mathrm{KW}$ \\
\hline Rotor copper losses & $15.524 \mathrm{KW}$ \\
\hline Stator iron losses & $1.449 \mathrm{KW}$ \\
\hline Rotor iron losses Iron losses & $1.449 \mathrm{KW}$ \\
\hline
\end{tabular}

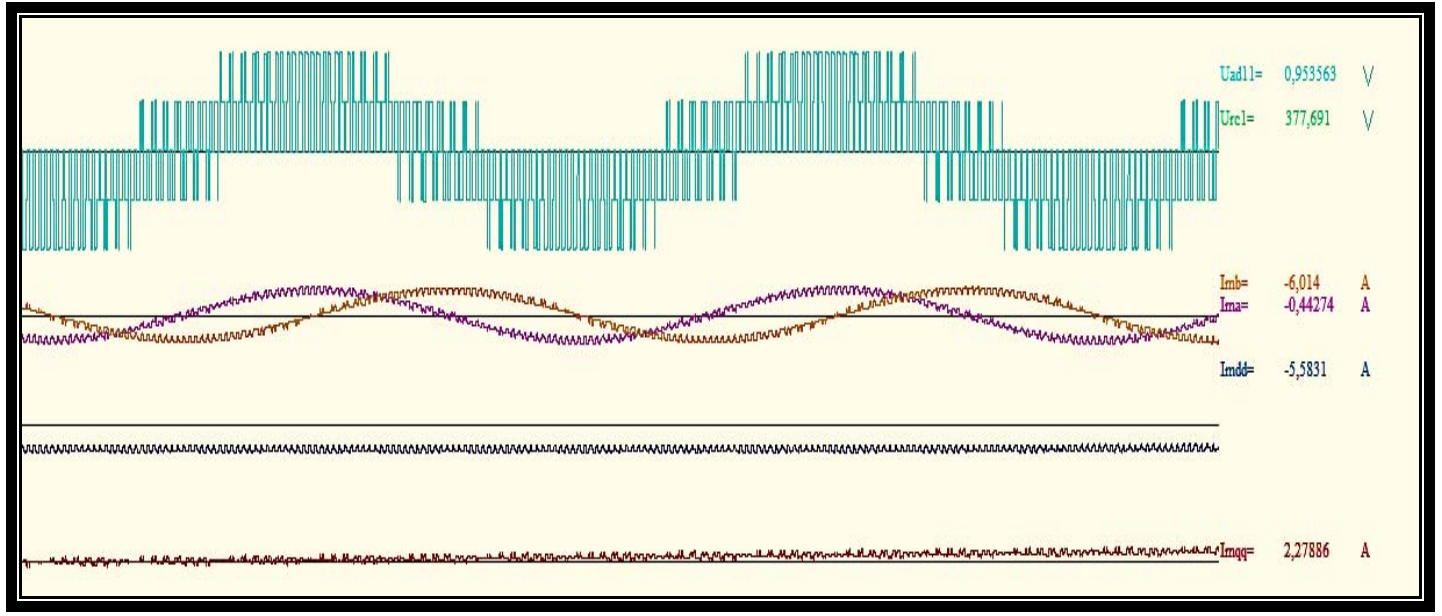

Figure 5 Schemes of characteristics voltage and current $\left(\mathrm{U}_{\mathrm{ad} 11}, \mathrm{U}_{\mathrm{rcl}}, \mathrm{I}_{\mathrm{mb}}, \mathrm{I}_{\mathrm{mdd}}\right.$, and $\left.\mathrm{I}_{\mathrm{mqq}}\right)$ 


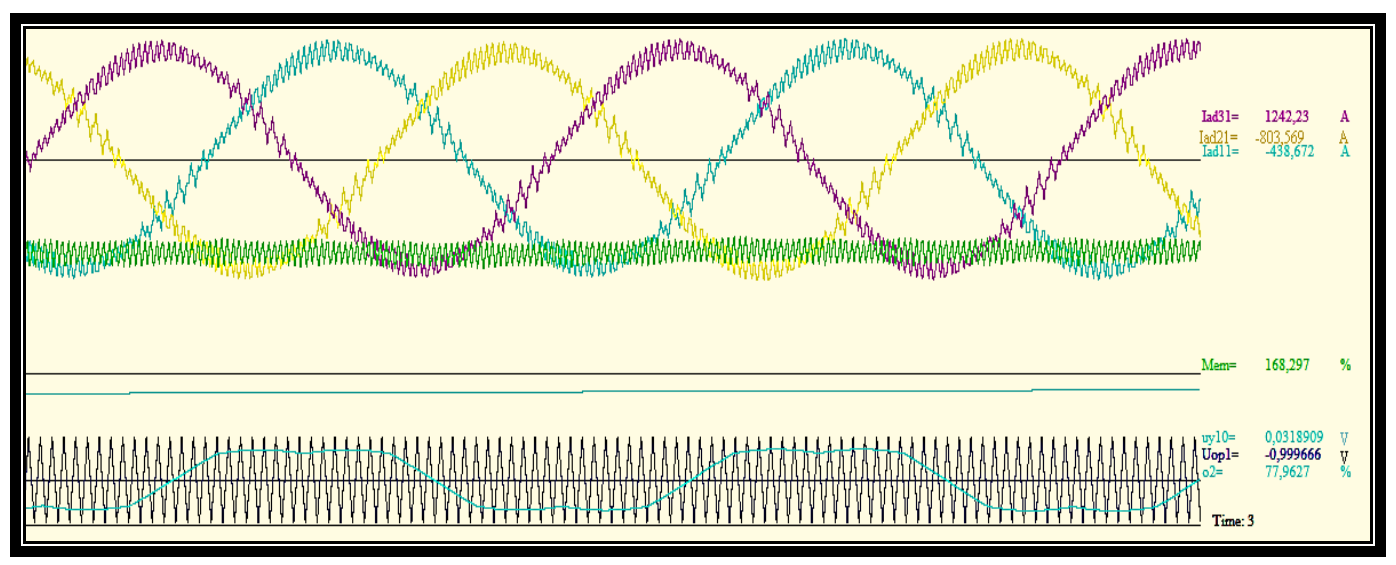

Figure 6 Characteristic current, torque and voltage $\left(\mathrm{I}_{\mathrm{ad1} 1}, \mathrm{I}_{\mathrm{ad} 21}, \mathrm{I}_{\mathrm{ad} 31}, \mathrm{M}_{\mathrm{ed}} \%, \mathrm{U}_{\mathrm{yo1}}, \mathrm{U}_{\mathrm{op}}\right.$ and $\left.\mathrm{O}_{2}\right)$

Table(5) Harmonic analysis when $\mathrm{L}_{\mathrm{r} 2} 0.015,0.003$ and 0.o126. pu

\begin{tabular}{|c|c|}
\hline Name & Value/Units \\
\hline Input capacitor voltage & $388.761 \mathrm{~V}$ \\
\hline Stator copper losses & $17.766 \mathrm{KW}$ \\
\hline Rotor copper losses & $16.065 \mathrm{KW}$ \\
\hline Stator iron losses & $1.486 \mathrm{KW}$ \\
\hline Rotor iron losses Iron losses & $1.486 \mathrm{KW}$ \\
\hline
\end{tabular}

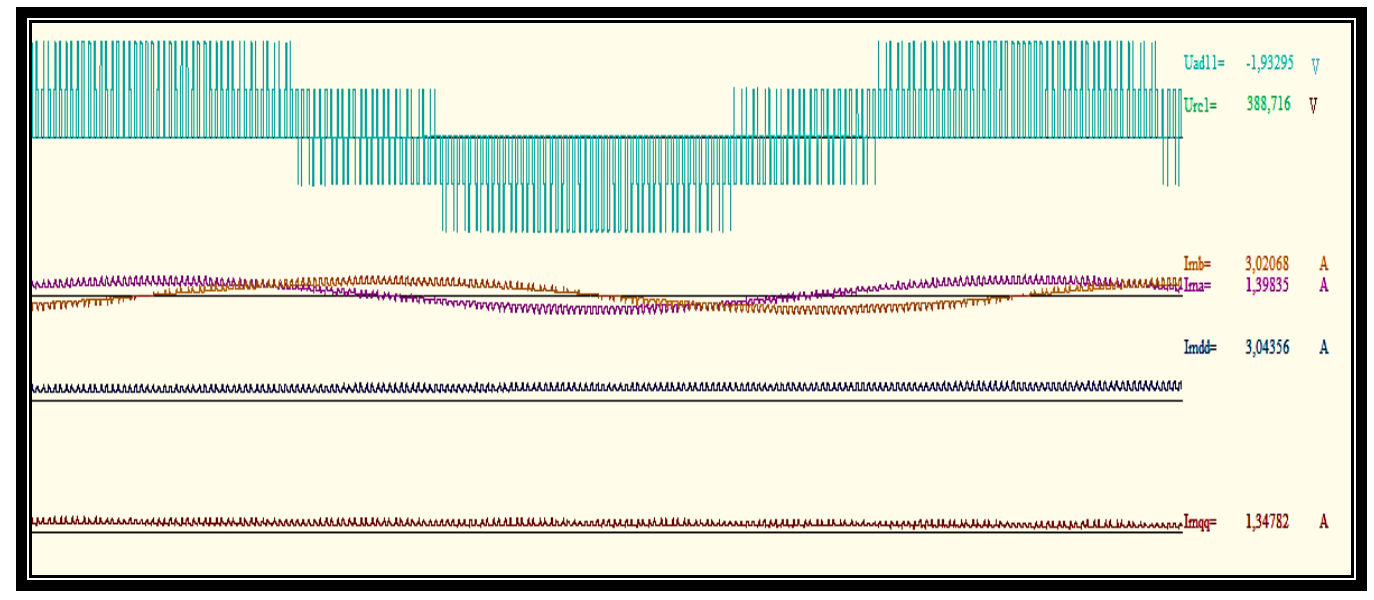

Figure 7 Schemes of characteristics voltage and current $\left(\mathrm{U}_{\mathrm{ad} 11}, \mathrm{U}_{\mathrm{rcl}}, \mathrm{I}_{\mathrm{mb}}, \mathrm{I}_{\mathrm{mdd}}\right.$, and $\left.\mathrm{I}_{\mathrm{mqq}}\right) \mathrm{L}_{\mathrm{r} 2} 0.015,0.003,0.0126 . \mathrm{pu}$

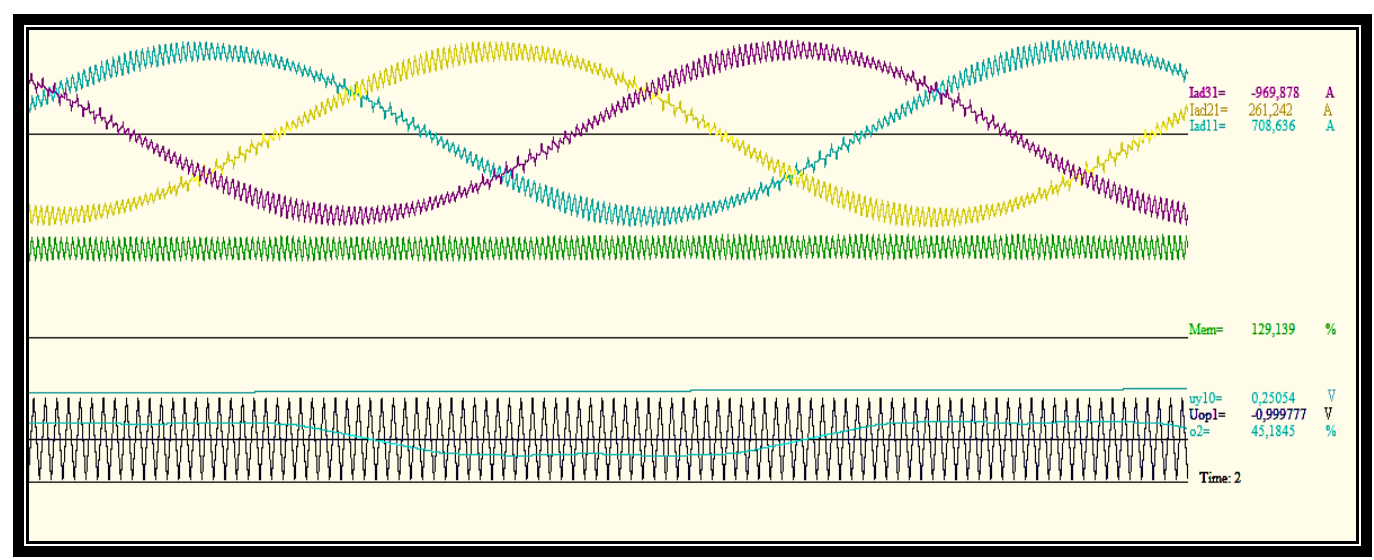

Figure 8 Characteristic, torque current and voltage of SC $\left(\mathrm{I}_{\mathrm{ad} 11}, \mathrm{I}_{\mathrm{ad} 21}, \mathrm{I}_{\mathrm{ad} 31}, \mathrm{Med} \%, \mathrm{U}_{\mathrm{yol}}, \mathrm{U}_{\mathrm{op}}\right.$ and $\left.\mathrm{O}_{2}\right)$ 
Table (6) Harmonic analysis. $0.2,0.24$ and 0.28 pu

\begin{tabular}{|c|c|}
\hline Name & Value/Units \\
\hline Input capacitor voltage & $377.95 \mathrm{~V}$ \\
\hline Stator copper losses & $8.725 \mathrm{KW}$ \\
\hline Rotor copper losses & $118.181 \mathrm{KW}$ \\
\hline Stator iron losses & $2.151 \mathrm{KW}$ \\
\hline Rotor iron losses Iron losses & $2.151 \mathrm{KW}$ \\
\hline
\end{tabular}

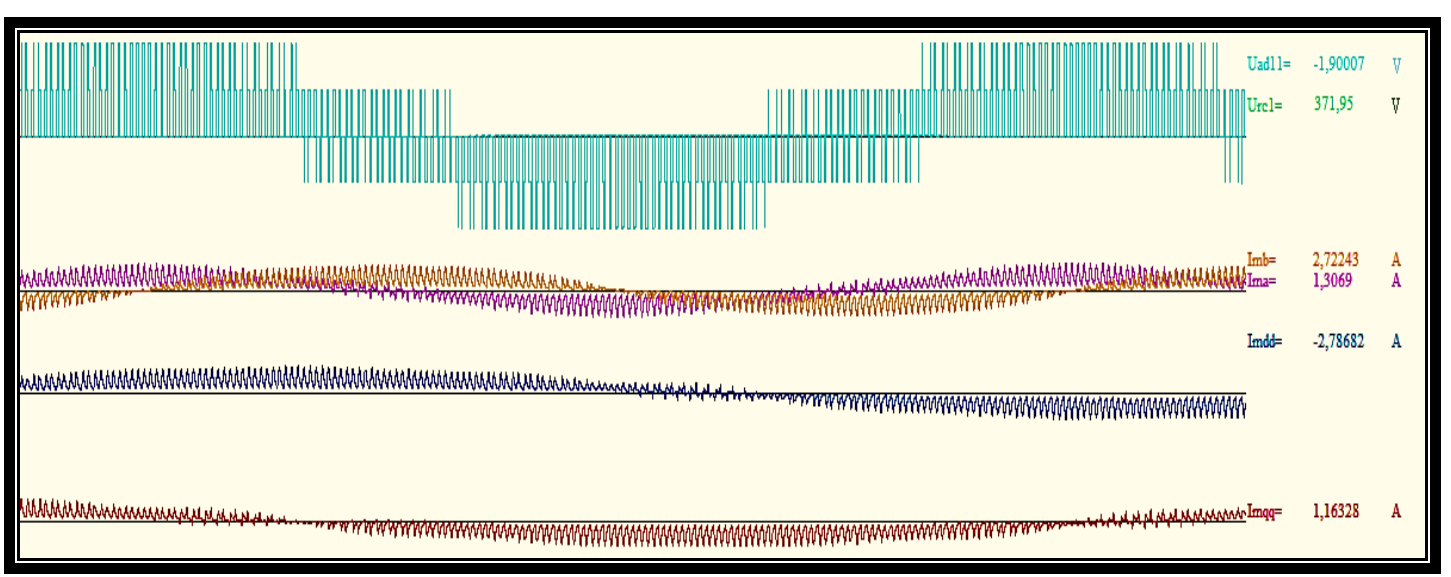

Figur9 Schemes of characteristics voltage and current $\left(\mathrm{U}_{\mathrm{ad} 11}, \mathrm{U}_{\mathrm{rc}}, \mathrm{I}_{\mathrm{mb}}, \mathrm{I}_{\mathrm{mdd}}\right.$, and $\left.\mathrm{I}_{\mathrm{mqq}}\right)$

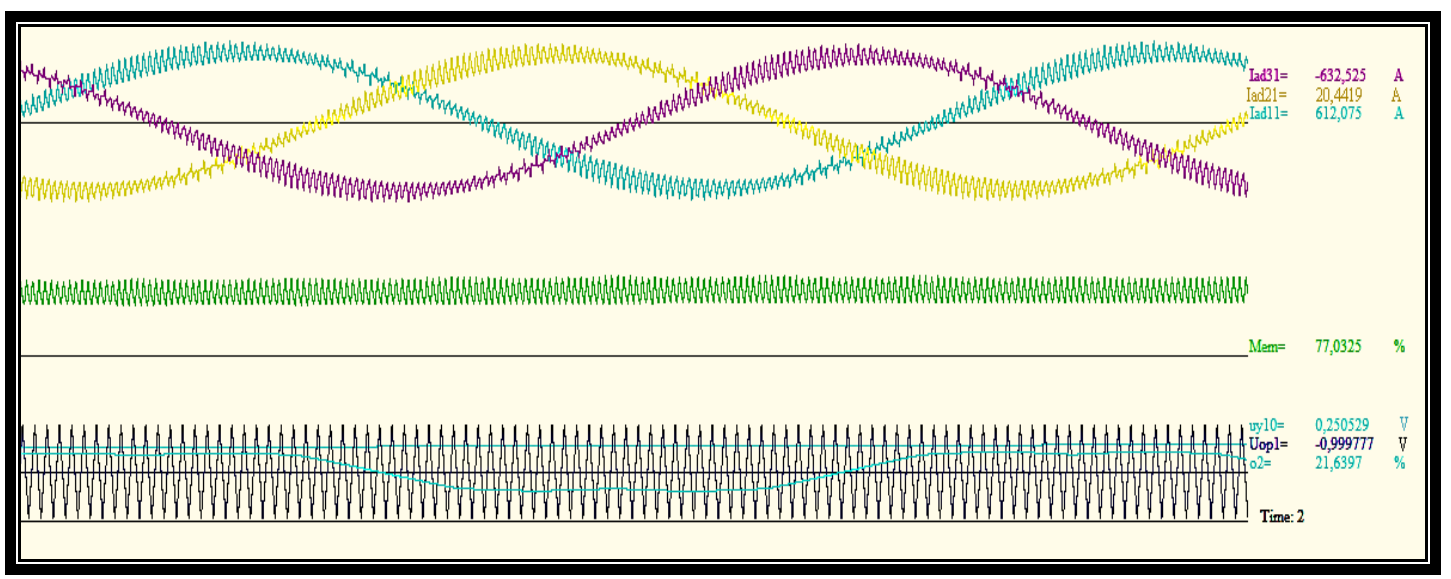

Figure 10 Schemes of characteristics torque voltage and current (Uad1 $1, \mathrm{U}_{\mathrm{rc}}, \mathrm{I}_{\mathrm{mb}}, \mathrm{I}_{\mathrm{mdd}}$, and $\mathrm{I}_{\mathrm{mqq}}$ ) $0.2,0.24,0.288$

\section{CONCLUSION}

THE Built up Model (MATHEMATICAL Driving Model) AND THE THREE-STAGE, A TWO-LEVEL INVERTER DESIGN IS DONE BY INTERCONNECTED MODEL AND C++, C BUILDER FOR THE CALCULATION OF TRANSIENT OR STEADY- STATE REGION PROVIDING SUITABLE DATA. THE IMPACT OF THE CURRENT DISTRIBUTION IN THE ROTOR TO START BEING USED IN BUILDING THE MODEL PROVED TRUE FOR EVALUATING THE CHARACTERISTICS OF LOSSES BY PWM WITH HIGH FREQUENCY (1000)HZ BY INCREASING LEAKAGE FLUX OF ROTOR WINDING AND STATOR INCREASE THE COPPER LOSSES FOR THERE MORE THE HEATING OF MACHINE AND THEN INSTANTLY THE STEEL LOSSES WILL GROWTH IT CAN BE USED IN REAL-TIME MODE WITH THE HELP OF PERSONAL COMPUTERS. THE SYSTEM IS DESIGNED FOR IGBT TRANSISTOR MODULES TO PROCESSORS BASED AND BASED ON THE USE OF MATHEMATICAL MODELS TO CONTROL SYSTEM. AS A RESULT THE LOSSES HAS BEEN MINIMIZED TO UP TO (5-10\%)OF TOTAL LOSSES .FURTHERMORE IT CAN BE REDUCED THE HARMONICS OF THE INVERTER BY USING HIGH RETE FREQUENCY.

\section{ACKNOWLEDGMENT}

I sincerely acknowledge the support of received from Dr. M.S. Hasan and my family and all those whose helped me at dayala university during may writing possesses . 


\section{REFERENCES}

[1] M Pronin. Simulation and analysis of the system with multiphase induction generator and multi-stage active rectifier/ Electrotechnika, 2006, №5. -p. 55-61. Russia

[2] M Pronin., Vorontsov A. Dependence of current pulsations of multi-phase electrical machine on reduction of winding pitch and scheme of semiconductor converter. EPE-PEMC 2006, Portoroz, Slovenia.

[3] C Cester., Kedous -Lebouc A., Cornut B. Iron loss under practical working conditions of a PWM powered induction motor. Magnetics, IEEE Transactions Sep 1997, Vol. 33, Issue 5, Part 2, pp. 3766-3768.

[4] A. J Moses., F Anayi. Effect of PWM Voltage Excitation in Iron Loss of Inverter Fed Motors. IEEE Transactions on Magnetics. 2004, vol. 40 (2), no 2, pp. 762-765.

[5] A Ruderman., R Welch. Electrical Machine PWM Loss Evaluation Basics. EEMODS 2005, 5 - 8 September 2005. Heidelberg / Germany.

[6] N Serov., P Kalachikov., M Pronin., A Vorontsov. Electro-transmission of dump trucks BelAZ with capacity up to $136 \mathrm{t} / /$ An. "Mining equipment and electro mechanics", 2005, №5. -p. 22-25. Russia

[7] М. В Пронин,., et al. "Электроприводы и системы с электрическими машинами и полупроводниковыми преобразователями (моделирование, расчет, применение). " ЕА Крутякова СПб, «Силовые машины »ґЭлектросила»,-2004.-252 с (2004).

[8] Г Корн., Т Корн. Справочник по математике для научных работников и инженеров. М., «Наука», 1978. 832 с.

[9] Пронин, МИХАИЛ ВАСИЛЬЕВИЧ, and А. Г. Воронцов. Силовые полностью управляемые полупроводниковые преобразователи (моделирование и расчет). СПб.: ОАО" Электросила", 2003.

[10] М. В Пронин., А. Г Воронцов., П. Н Калачиков., А. П Емельянов. Электроприводы и системы с электрическими машинами и полупроводниковыми преобразователями (моделирование, расчет, применение) Под редакцией Крутякова Е. А. «Силовые машины» «Электросила» Санкт-Петербург 2004 год.

\section{AUTHOR PROFILE}

AHMED IBRAHIM JABER received his B.Sc. from University of Diyala /Iraq in 2006 from power and electrical machine department, MSc from Saint-Petersburg Electro technical University "LETI" in Faculty of Industrial Automation and Electrical Engineering in 2013 .He is currently Assist .Lecturer in the Department of Electrical Power Engineering, College of Engineering University of Diyala Iraq 